\title{
Missing ethnic information in current BRCA variant databases
}

\author{
Zixin Qin ${ }^{1}$ and San Ming Wang ${ }^{1}$ \\ ${ }^{1}$ University of Macau
}

July 16, 2020

\begin{abstract}
BRCA variation is highly ethnic-specific. Our analysis of major BRCA reference databases shows that nearly all databases except BIC do not provide ethnic information for their collected BRCA variants. We consider that inclusion of ethnic information of BRCA variants is necessary as it will benefit the study of human BRCA evolution, understand ethnic-basis of BRCA variation and cancer, and promote ethnic-based clinical applications in diversified ethnic populations.
\end{abstract}

\section{Missing ethnic information in current $B R C A$ variant databases}

Zixin Qin, San Ming Wang

To the Editor,

$B R C A$ mutation substantially increases risk of breast and ovarian cancer. Extensive efforts have identified large quantities of human $B R C A 1$ and $B R C A 2$ ( $B R C A$ ) variants, and the data have been developed into multiple $B R C A$ variant reference databases to guide clinical applications worldwide. Human $B R C A$ genes are rapidly evolving (Huttley et al, 2000; Lou et al, 2014). This is reflected by the highly ethnic-specific nature of human BRCA variation (Rebbeck et al, 2018; Kwong et al, 2016; Bhaskaran et al, 2019). For example, $B R C A$ variation in Africans is substantially different from non-Africans that nearly $90 \%$ of $B R C A$ variants in Africans were not present in non-Africans (Figure 1) (Shen et al, 2000; John et al, 2007; Churpek et al, 2015; Zheng et al, 2018; Fiebel et al, 2019). Ethnic-specific BRCA variation is important for understanding the evolution of human $B R C A$, genetic basis of $B R C A$ variation and cancer, and for using ethnic-based variation information for precise diagnosis, prevention and treatment of $B R C A$ related cancer in diversified ethnic populations.

To understand current knowledge of ethnic-specific $B R C A$ variation, we analyzed the ethnic information in the major BRCAdatabases including BRCA Exchange, ClinVar, ENIGMA, LOVD, BIC, BRCA-share and ARUP. The results show that except BIC, the current BRCA databases basically do not provide ethnic information for their collected $B R C A$ variants (Figure 1B). The reason for lack of ethnic information in current BRCA databases can be that submitters do not provide the ethnic information as considered it unnecessary. This needs to be changed by the increased evidence in ethnic-specific $B R C A$ variation and its relevant in cancer application. Another reason can be that ethnic origin is classified as private information being protected by law, therefore, both submitters and database curators don't want to include ethnic information. However, the $B R C A$ data in public $B R C A$ databases are all anonymous such that ethnic information is not relevant to privacy issue.

We believe that the ethnic information needs to be included in current BRCA variant databases to benefit clinical applications.

\section{ACKNOWLEDGMENTS}


This work was supported by grants from the University of Macau (SRG2017-00097-FHS, MYRG2019-00018FHS, FHSIG/SW/0007/2020P).

\section{CONFLICT OF INTERESTS}

The authors declare that there are no conflict of interests.

\section{Correspondence}

San Ming Wang

Faculty of Health Sciences, University of Macau

Taipa, Macau SAR, China.

Email: sanmingwang@um.edu.mo

\section{ORCID}

San Ming Wang @ http://orcid.org/ 0000-0002-2172-1320

\section{References}

Bhaskaran, S. P., Chandratre, K., Gupta, H., Zhang, L., Wang, X., Cui, J., .. \& \&ang, S. M. (2019). Germline variation in BRCA1/2 is highly ethnic-specific: Evidence from over 30,000 Chinese hereditary breast and ovarian cancer patients. International journal of cancer , 145 (4), 962-973. https://doi.org/10.1002/ijc.32176

Churpek, J. E., Walsh, T., Zheng, Y., Moton, Z., Thornton, A. M., Lee, M. K., .. \& Olopade, O. I. (2015). Inherited predisposition to breast cancer among African American women. Breast cancer research and treatment , 149 (1), 31-39. https://doi.org/10.1007/s10549-014-3195-0

Friebel, T. M., Andrulis, I. L., Balmaña, J., Blanco, A. M., Couch, F. J., Daly, M. B., ...\& Rebbeck, T. R. (2019). BRCA1 and BRCA2 pathogenic sequence variants in women of African origin or ancestry. Human mutation , 40 (10), 1781-1796. https://doi.org/10.1002/humu.23804

Huttley, G. A., Easteal, S., Southey, M. C., Tesoriero, A., Giles, G. G., McCredie, M. R., Hopper, J. L., \& Venter, D. J. (2000). Adaptive evolution of the tumour suppressor BRCA1 in humans and chimpanzees. Australian Breast Cancer Family Study. Nature genetics , 25 (4), 410-413. https://doi.org/10.1038/78092

John, E. M., Miron, A., Gong, G., Phipps, A. I., Felberg, A., Li, F. P., West, D. W., \& Whittemore, A. S. (2007). Prevalence of pathogenic BRCA1 mutation carriers in 5 US racial/ethnic groups. JAMA , 298 (24), 2869-2876. https://doi.org/10.1001/jama.298.24.2869

Kwong, A., Shin, V. Y., Ho, J. C., Kang, E., Nakamura, S., Teo, S. H., .., \& Kim, S. W. (2016). Comprehensive spectrum of BRCA1 and BRCA2 deleterious mutations in breast cancer in Asian countries. Journal of medical genetics , 53 (1), 15-23. https://doi.org/10.1136/jmedgenet-2015-103132

Lou, D. I., McBee, R. M., Le, U. Q., Stone, A. C., Wilkerson, G. K., Demogines, A. M., \& Sawyer, S. L. (2014). Rapid evolution of BRCA1 and BRCA2 in humans and other primates. BMC evolutionary biology , 14, 155. https://doi.org/10.1186/1471-2148-14-155

Rebbeck, T. R., Friebel, T. M., Friedman, E., Hamann, U., Huo, D., Kwong, A., .. Nathanson, K. L. (2018). Mutational spectrum in a worldwide study of 29,700 families with BRCA1 or BRCA2 mutations. Human mutation , 39 (5), 593-620. https://doi.org/10.1002/humu.23406

Shen, D., Wu, Y., Subbarao, M., Bhat, H., Chillar, R., \& Vadgama, J. V. (2000). Mutation analysis of BRCA1 gene in African-American patients with breast cancer. Journal of the National Medical Association , $92(1), 29-35$. 
Zheng, Y., Walsh, T., Gulsuner, S., Casadei, S., Lee, M. K., Ogundiran, T. O., ... Olopade, O. I. (2018). Inherited Breast Cancer in Nigerian Women. Journal of clinical oncology : official journal of the American Society of Clinical Oncology , 36 (28), 2820-2825. https://doi.org/10.1200/JCO.2018.78.3977

\section{Figure legends}

Figure 1. Ethnic $B R C A$ variants. A. Comparison of $B R C A$ variants between African and non-African populations. A total of $302 B R C A 1$ and $351 B R C A 2$ variants originated from Africans were identified from literatures, and compared with the 1,051 BRCA1 and 2,145 BRCA2 variants with ethnic information in $B R$ $C A$ Exchange Database after removal of its African-derived variants (https://brcaexchange.org). The results show that $86 \%$ of $B R C A 1$ variants and $91 \%$ of $B R C A 2$ variants from Africans were not shared with these derived from non-Africans; B. Ethnic information in current major BRCA variant databases. It shows the information is not present in most of the databases except in BIC.

A.

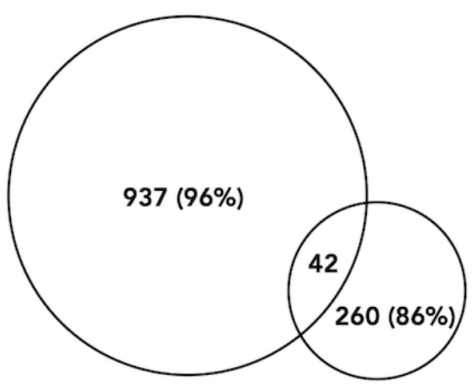

non-Africans
Africans

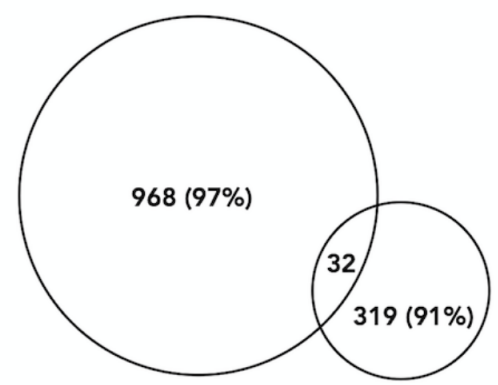

non-Africans

Africans

BRCA2

B.

\begin{tabular}{|c|c|c|c|c|c|c|}
\hline \multirow[t]{2}{*}{ Databases } & \multicolumn{2}{|r|}{ BRCA1 } & \multicolumn{2}{|r|}{ BRCA2 } & \multicolumn{2}{|r|}{ BRCA } \\
\hline & Total & with ethnic info. (\%) & Total & with ethnic info. (\%) & Total & with ethnic info. (\%) \\
\hline BRCA share & 2495 & 0 & 3454 & 0 & 5949 & 0 \\
\hline ARUP & 1823 & 0 & 2103 & 0 & 3926 & 0 \\
\hline BED & 19276 & $1051(5)$ & 20068 & $1094(5)$ & 39344 & $2145(5)$ \\
\hline BIC & 1702 & $1051(62)$ & 1916 & $1094(57)$ & 3618 & 2145 (59) \\
\hline LOVD & 4800 & $852(18)$ & 6134 & $836(14)$ & 10934 & $1688(15)$ \\
\hline Clinvar & 7787 & $1036(13)$ & 11538 & $1092(9)$ & 19325 & 2128 (11) \\
\hline ENIGMA & 3340 & 569 (17) & 4105 & $530(13)$ & 7445 & 1099 (15) \\
\hline
\end{tabular}

